\title{
A Novel Effect of Solanum Tuberosum/Zn-30Al-7Ti Sulphate Modified Coating on UNS G10150 Mild Steel Via Dual-anode Electrodeposition Route
}

\author{
T. Monyai, ${ }^{a}$ O.S.I Fayomi ${ }^{a, b,}{ }^{*}$ and A.P.I Popoola ${ }^{a}$ \\ ${ }^{a}$ Department of Chemical, Metallurgical and Materials Engineering, Tshwane University of \\ Technology, P.M.B. X680, Pretoria, South Africa \\ ${ }^{b}$ Department of Mechanical Engineering, Covenant University, P.M.B 1023, Ota, Nigeria
}

Received September 11, 2016; accepted October 6, 2016

\begin{abstract}
UNS G10150 steel was electrodeposited with Zn-30Al-7\%Ti, in the presence of solanum tuberosum, under sulphate condition, via dual anode route. The microstructures of the deposited layers were examined using scanning electron microscopy (SEM), atomic force microscope and X-ray diffractometry (XRD). The microhardness properties and wear characteristics were performed using a diamond based microhardness tester and a CERT reciprocating sliding tester. The microstructure revealed a massive structural transformation with hexagonal dendritic and whisker-like structure for the Zn-30Al-7\% Ti coating. There was a significant rise in surface micro hardness values of the co-deposited layers, due to the presence of hard phase $\mathrm{TiO}_{2}$ particles, and solanum precipitation. The surface strengthening effect induced by solanum, and $\mathrm{Al} / \mathrm{TiO}_{2}$ addition, with the presence of $\mathrm{Zn}_{2} \mathrm{Al}_{3} \mathrm{Ti}_{2}$, could be responsible for low plastic deformation and improved hardness of the coating. It is established that the electrodeposition route via dual anode of Zn-Al-Ti with adsorbed fluid on UNS G10150 steel can be used to improve the surface hardness values, aesthetic properties and wear resistance.
\end{abstract}

Keywords: Solanum tuberosum; wear; dual anode; coating; microstructure.

\section{Introduction}

Protective coatings are perhaps the most extensively used surface modification technique to avert failure in manufacturing industries for metals. They are used to provide long-term protection under a broad range of wear and structural deformation, ranging from atmospheric contact to the most demanding mechanical processing conditions [1,2]. Although surface coatings must provide a continuous barrier to a substrate such as mild steel, any imperfection can become the focal point for degradation of the substrate, if not carefully

\footnotetext{
* Corresponding author. E-mail address: ojosundayfayomi3@gmail.com, ojo.fayomi@covenantuniversity.edu.ng
} 
fabricated. The quality of a coating depends on many factors besides the nature of the materials involved [3].

Coating and metal finishing operations are intended to increase abrasion resistance, alter appearance, serve as an improved base for the adhesion of other materials, enhance wear and frictional characteristics, add hardness and improve electrical properties [4]. Electrodeposition is an appreciable technique that has been known to improve functional and high performance applications, especially with thin film fabrication, for outstanding wear deformation resistance, improved hardness, and suitable structural characteristics $[5,6]$.

Acceptable coatings in co-deposition technique are generally characterized by a good adhesion of the coating to the substrate, and low porosity [7]. To achieve this unique objectives, composite deposition has recently gained full acceptability, due to its unique properties in industry application, such as automobile, aerospace, marine and construction, to mention but a few.

However, the life span of such coatings is limited, due to the hostile nature of some environments, especially during service. With the purpose to restrain this difficulty, surfactants are often employed [8]. The use of surfactants could allow an exact composition of the deposit. Facts have also established that a suitable surfactant not only improves the stability of suspension by increasing the wettability of the particles, but also boosts the electrostatic adsorption of suspended particles on the cathode surface, by increasing their positive charge [9]. Surfactant and organic compounds are known as additives applied to enhanced zinc plating, and studies have widely showed that they achieve robust and solid zinc coatings for corrosion prevention. These additives affect deposition and crystal-building progressions. From adsorption phenomena, so that surfactant incorporation is effective, there is a chemical combination between the substrate and the adsorbate where electrons are transferred.

Some surfactants in deposition also serve as coating binders, which provide uniformity and coherence to the coating system [10-12]. Not all binders are corrosion resistant; hence, some of them serve in the preparation of protective coatings. The binder's capacity to produce a dense and tight film is directly linked to its molecular size and complexity [13]. The electrodeposition of suspended inert particles into a growing metal matrix seems to offer a possible solution to this problem of deformation, and has attracted research interest, due to its unique functional properties, such as improved wear resistance and lubricity. Additionally, its combination with an inhibitive fluid could be seen to guarantee good characteristics [14]. Glycerin, thiourea, SiC and others are reported as examples of additional inorganic and metallic ingredients that perform such role of improving coatings properties. However, research has been developing more the use of nontoxic, cheap organic juice extraction as an alternative to toxic and expensive additives $[15,16]$.

In this study, solution-based processing methods via dual anode electrodeposition were targeted to fabricate a ternary based composite coating induced with solanum tuberosum, with the aim to provide resilient compatible structural properties, improve hardness, and mitigate significantly wear propagation. 


\section{Materials and method \\ Materials}

A flat mild steel plate $(20 \mathrm{~mm} \times 20 \mathrm{~mm} \times 20 \mathrm{~mm})$ substrate was used in this study. The elemental composition of the steel obtained from the spectrochemical analysis is as it follows: C 0.15; Mn 0.45; Si 0.18; P 0.01; S 0.031; Al 0.005; Ni 0.008; Fe balance. Other materials employed for the purpose of this work include pure zinc plate anode, zinc chloride, glycine, thiourea, Al (45 nm, $97 \%$ purity) and Tin IV oxide (25 nm, $99.7 \%$ purity), which were purchased from Sigma, South Africa. Potato tubers (solanum) of equivalent weight $(2.5 \mathrm{~kg}$ ) were selected and cut into smaller pieces and squeezed to remove the fluid. The extracted juice was stored in clean airtight bottles and refrigerated. The potato tuber (solanum tuberosum) (Fig. 1) used was purchased from a vendor in Pretoria, South Africa.

\section{Method}

The mild steel plate was sectioned using high precision automatic strewers, cutoff into $20 \mathrm{~mm}$ by $20 \mathrm{~mm}$, and further dipped into a $1 \mathrm{M}$ of $\mathrm{HCl}$ solution for 10 seconds, followed by rinsing into de-ionized water. Analytical grade chemicals and de-ionized water were used to prepare the plating solutions at $35^{\circ} \mathrm{C}$, to easily dissociate any agglomerate in the bath. During the plating, the cathode and the dual anode of the zinc plate $(40 \mathrm{~mm}$ by $50 \mathrm{~mm}$ ) were connected to the copper rod via a conductive wire, and passed to the rectifier terminal. The solution was stirred using the magnetic stirrer, so that it could plate well on the mild steel. The bath compositions for the coatings are as it follows: $\mathrm{Zn}, 75 \mathrm{~g} / \mathrm{L} ; \mathrm{Al}, 30 \mathrm{~g} / \mathrm{L}$; KCl, $50 \mathrm{~g} / \mathrm{L}$; boric acid, $10 \mathrm{~g} / \mathrm{L}$; $\mathrm{TiO}_{2} 7 \mathrm{~g} / \mathrm{L} ; \mathrm{ZnSO}_{4} 75 \mathrm{~g} / \mathrm{L}, \mathrm{pH}$, 4.8; voltage $0.3 \mathrm{~V}$; time, $20 \mathrm{~min}$; temperature $40{ }^{\circ} \mathrm{C}$; current density of $0.5 \mathrm{~A} / \mathrm{cm}^{2}$; stirring rate 200 rpm; glycine $10 \mathrm{~g} / \mathrm{L}$. The solution was prepared two weeks before the plating, before the deposition of the $\mathrm{Zn}-\mathrm{Al}-\mathrm{TiO}_{2}$-solanum. The rinsing was done in distilled water for 5 seconds, and it was later air dried.

\section{Characterization of the electrodeposited samples}

The X-ray diffraction (XRD) patterns of the samples were obtained with an

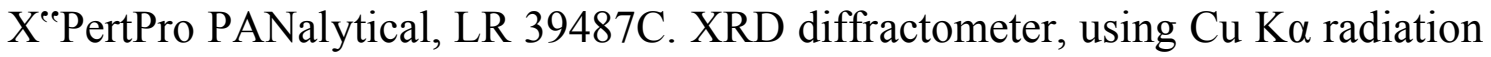
$(40 \mathrm{kV}, 40 \mathrm{~mA})$. Stepwise increase for small angle rate was $0.01^{\circ}$ over the range of 1 to $8^{\circ}$, and for wide angle rate was $1^{\circ} 2 \theta \mathrm{min}^{-1}$, over the range of 8 to $90^{\circ}(2$ $\theta$ ). The morphology of the deposited sample was further examined by scanning electron microscopy, using a JEOL JSM 6390 electron microscope and optical microscope. An Emco-test micro-hardness tester machine was used for determining the hardness values of the samples. Indentation of five points and 15 seconds dwell with $100 \mathrm{~g}$ load were used in this work, and average picked. 

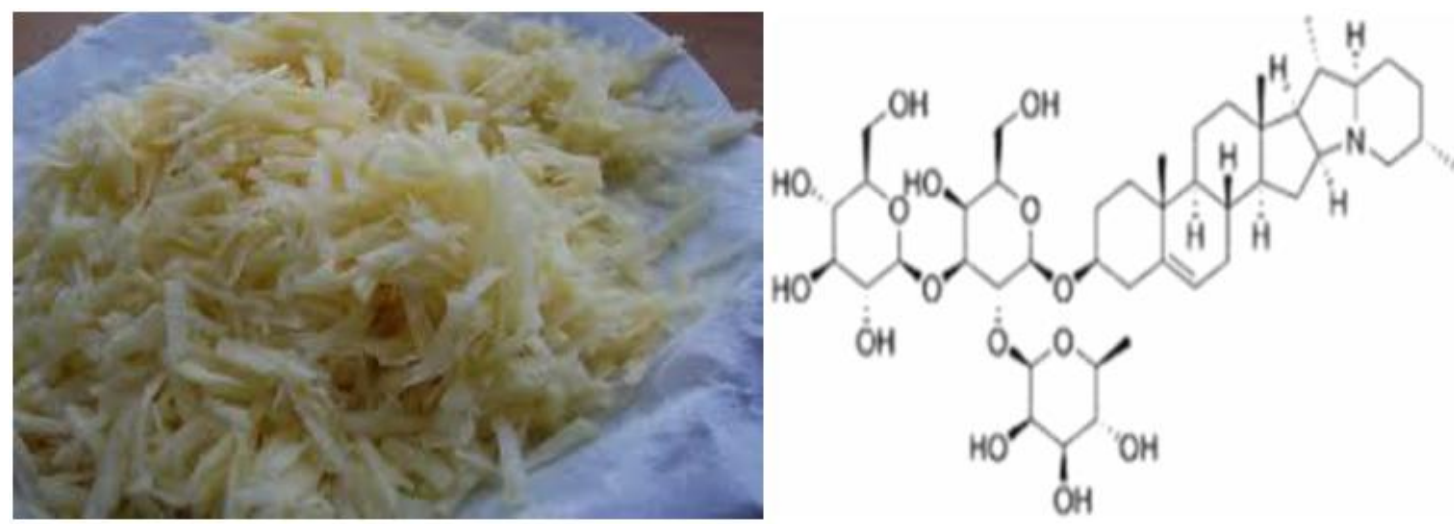

Figure 1. Crushed solanum to obtain solanum juice, and its molecular structure.

Reciprocating ball-on-flat sliding wear tests were performed on a (CETR UMT2) tribometer. For sliding wear tests, a $20 \times 20 \mathrm{~mm}$ coated mild steel substrate was cut, and an aluminum ball of $10 \mathrm{~mm}$ diameter was engaged as counterface. The tests were performed under a load of $5 \mathrm{~N}$ with a distance of $2,000 \mathrm{~m}$, oscillating frequency of $5 \mathrm{~Hz}$, and wear stroke length of $2 \mathrm{~mm}$. The prepared bath chemical formulation for $\mathrm{Zn}-\mathrm{Al}-\mathrm{TiO}_{2}$-solanum sulphate electrolyte matrixes and their corresponding effects on the physical properties are presented in Table 1.

Table 1. Electrodeposition parameters and results for Zn-Al-Ti-S deposition.

\begin{tabular}{|l|c|c|c|c|c|c|}
\hline Samples & $\begin{array}{c}\text { Time } \\
(\mathbf{m i n})\end{array}$ & $\begin{array}{c}\text { Coating } \\
\text { thickness }(\boldsymbol{\mu m})\end{array}$ & $\begin{array}{c}\text { Weight } \\
\text { gain }(\mathbf{g})\end{array}$ & $\begin{array}{c}\text { Coating per unit } \\
\text { area }\left(\mathbf{m g} / \mathbf{m m}^{2}\right)\end{array}$ & $\begin{array}{c}\text { Voltage } \\
(\mathbf{V})\end{array}$ & $\begin{array}{c}\text { Additive } \\
\text { Concentration (g) }\end{array}$ \\
\hline As-received & - & - & - & - & - & - \\
\hline $\begin{array}{l}\text { Zn-30Al-7Ti-S+10 mL } \\
\text { Solanum }\end{array}$ & 20 & 198.0 & 0.4216 & 0.0501704 & 0.3 & 7 \\
\hline
\end{tabular}

\section{Results and discussion}

\section{Physical and structural characteristics}

The effect of dispersed composite particulates and the influence of applied potentials were observed on the hybrid coating. It is apparent that the massive movement of the bath particulates was supported by potential difference (see Table 1) and agrees with the report by [7]; that adsorption of the particulates, especially semiconductor particles and oxides on mild steel, could be obtained by influence of the process parameter, which would lead to an enhanced surface area. With $7 \mathrm{~g}$ of $\mathrm{TiO}_{2}$ and $10 \mathrm{~mL}$ of solanum fluid, an improved behaviour was obtained for the developed $\mathrm{Zn}-30 \mathrm{Al}-7 \mathrm{TiO}_{2}-\mathrm{S}-0.3 \mathrm{~V}$, with a weight gain of $0.42166 \mathrm{~g}$ and coating thickness of $198.0 \mu \mathrm{m}$. Although [8] has affirmed that, when there is a small change in concentration of the composite added into the bath (between $6 \mathrm{~g}$ to $13 \mathrm{~g}$ ), it is always expected a significant rise in weight gain. This interesting result is in line with the report by [9], that even a small change in concentration will promote significant behavioral change, due to the change in phase structure.

Fig. 2 compares the atomic force micrographs obtained from the composite fabricated alloy of $\mathrm{Zn}-\mathrm{Al}-7 \mathrm{Ti}-\mathrm{S}-0.3 \mathrm{~V}$ with as-received mild steel, respectively. It 
is apparent that with a $7 \mathrm{~g} \mathrm{TiO}_{2}$ particle concentration in the plating bath and 10 $\mathrm{mL}$ solanum, a good topographic modification was seen. The surface of the composite fabricated alloy of Zn-Al-7Ti-S-0.3V was dominated with nodular particles at different heights. The coating-strengthening capacity and the topography could be traced to the active composite loading and adsorption effect of solanum on zinc-aluminum matrix, resulting in good adhesion.

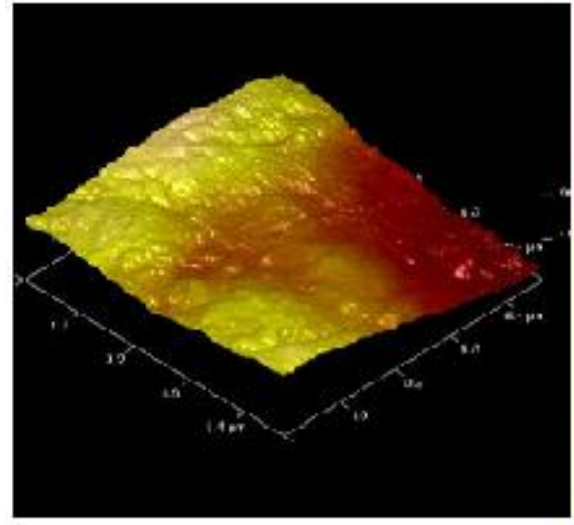

As-received

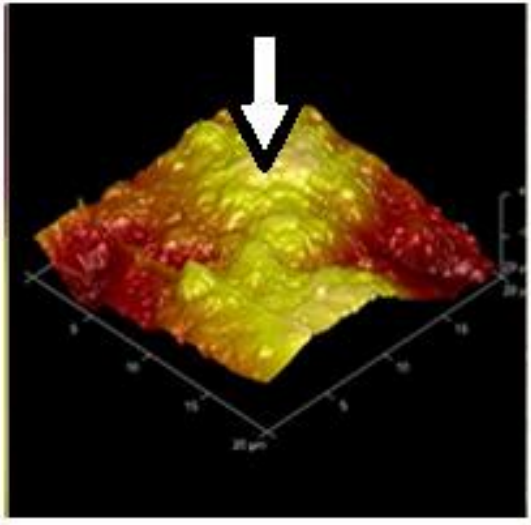

Zn-AI-Ti-Coated Steel

Figure 2. AFM morphology of as-received and Zn-Al-Ti-solanum alloy.

Fig. 3 represents the XRD patterns of the as-received sample with Fe presence at the interface. The Zn-Al-7Ti-S-0.3V alloy possesses suitable intermetallic phases with zinc hexagonal structure in the matrix, as described by [7].

The presence of $\mathrm{Al}$ and $\mathrm{TiO}_{2}$ particles could be seen to influence the peak intensity and crystallographic orientation of the zinc metal matrix compared to the control sample. In all solanum with $\mathrm{TiO}_{2}$, particulates play an incredible effect on the preferred orientation of the metal matrix, with revealed secondary phases of $\mathrm{Zn}_{2} \mathrm{Al}_{3} \mathrm{Ti}_{2}, \mathrm{Zn}_{3}$ Ti4 and $\mathrm{ZnOTi}$.

Fig. 4 shows the microstructural modification of $\mathrm{Zn}-\mathrm{Al}-\mathrm{TiO}_{2}$ sulphate deposition on mild steel. At $7 \mathrm{~g}$ of the composite, the coating exhibits a uniform deposit with hexagonal zinc crystal within the interface. A good refinement in grain structure and improved microstructure was observed. This result could be well interpreted by the full coverage of the incorporated additives, which helps to block the active site, as a result of the slow deposition rate.

The lustrous and homogeneous embedded grain of $\mathrm{TiO}_{2}$ particulates along the interface demonstrated that the role of particle incorporation depended on the mass transport phenomena, with other active agents' additive participation. Although $\mathrm{TiO}_{2}$ introduction into the zinc metal matrix has been attested as a seed for whiskers growth $[6,15]$, there is no doubt that the crystal growth and compactable orientation of $\mathrm{Zn}-\mathrm{Al}-7 \mathrm{Ti}-\mathrm{S}-0.3 \mathrm{~V}$ coating is influenced by swift activities of the solanum as adsorbate, and of $\mathrm{TiO}_{2}$ as metal matrix. 

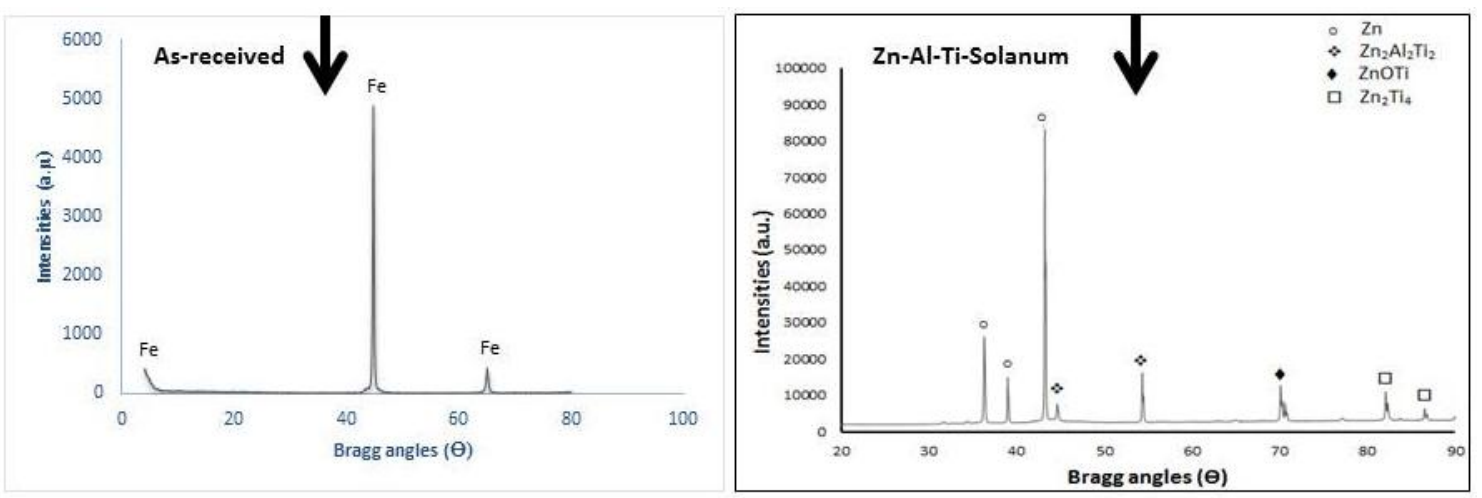

Figure 3. XRD pattern of as-received and Zn-Al-Ti-solanum alloy.

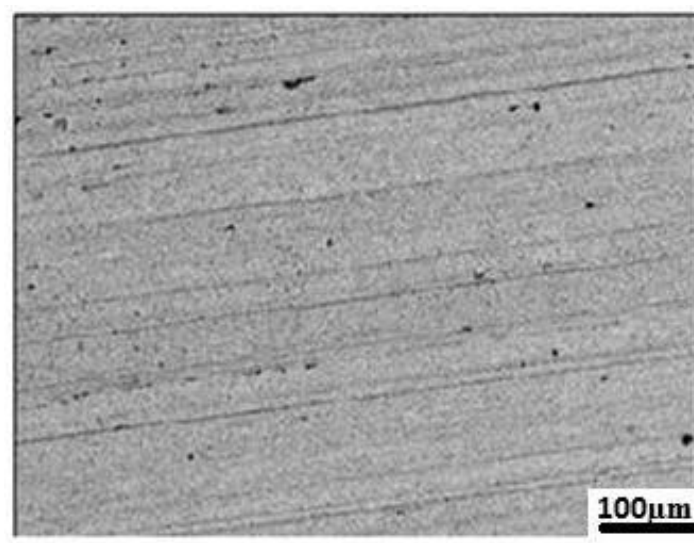

As-received

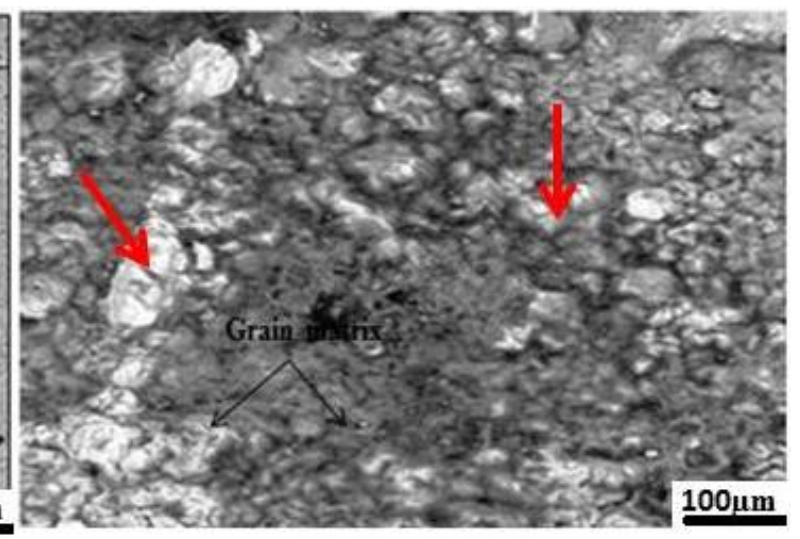

Zn-Al-Ti-Solanum

Figure 4. SEM structure of as-received and Zn-Al-Ti-solanum alloy.

Table 2 shows the microhardness and wear plastic deformation of as-received and of developed Zn-Al-7Ti-S-0.3 V coating.

With a load of $100 \mathrm{~g}$, spacing of $20 \mu \mathrm{m}$, and dwell time of $15 \mathrm{~s}$, the results indicate that the surface hardness of the deposited Zn-Al-7Ti-S-0.3 V composite coatings had an increased hardness compared to the base mild steel substrate. High hardness in the coatings is attributed to the formation of the uniform and fine grained produced microstructure. The presence of hard intermetallic phases as a result of the buildup in the microstructure also contributed immensely to the improved hardness properties.

The coated alloy has $331.3 \mathrm{HVN}$ compared to $34.5 \mathrm{HVN}$ of the as-received sample; this shows a significant geometric improvement. From the wear plastic deformation, it can be observed that the wear loss of the composite deposited coating decreases significantly compared to the un-plated sample. The results indicate that a relevant relationship exists between the incorporated particulates, the role of the solanum fluid and the rate of deposited cluster within the coating interface. The as-received sample has a very high wear loss, an indication of zero resistance of the surface active protective layer on the steel substrate. More so, it can also be said that the aluminum inclusion helped in the enhancement of the wear resistance [15], because-aluminum particles have a low level of electronic conductivity, and when they are relatively dispersed in the bath, they enhance co- 
existence of other metals, and probably reduce wear loss propagation. This fact confirms the assertion by [10].

Table 2. Hardness and wear test of as-received and Zn-Al-Ti-solanum alloy.

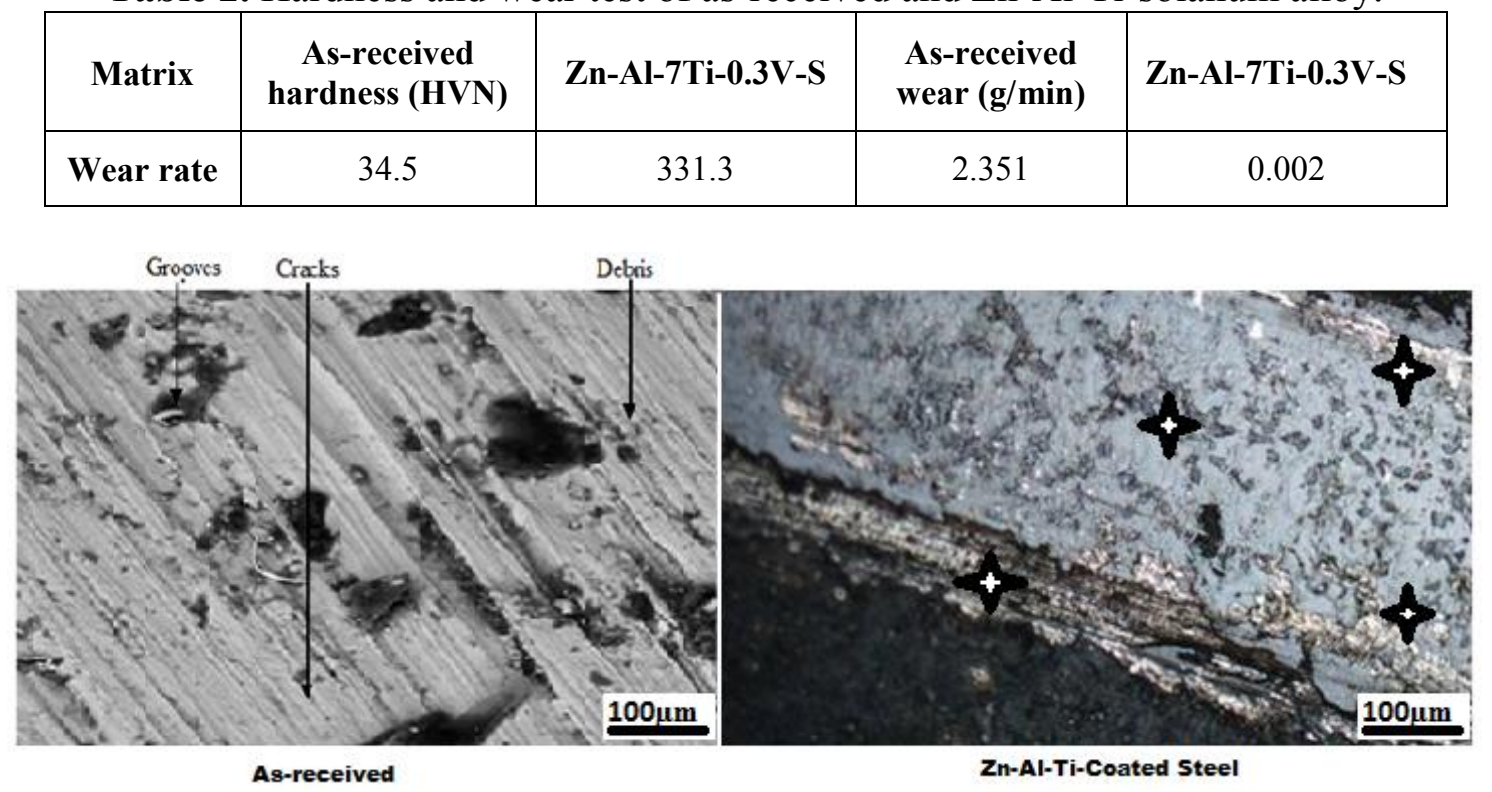

Figure 5. SEM wear scar of as-received and Zn-Al-Ti-solanum alloy.

Fig. 5 shows the micrographs of wear scars of the Zn-Al-7Ti-0.3V-S as-received steel and composite coating, respectively. Serious damage occurred for the base metal with revealed grooves and debris. It is evident that the absence of a protective layer is the reason for the un-resistible wear erosion observed within the mild steel substrate, as the counter-body swiftly has its way into the surface regions.

For the coated composite samples, the amount of wear debris produced within interface is significantly small. The plastic deformation was greatly retarded in the presence of the dispersive strengthening effect of the incorporated $\mathrm{TiO}_{2}$ solanum adsorbate and $\mathrm{Al}$ interlink into the zinc rich phase on the electrodeposited metal. Although during sliding process the reciprocating counter-face has great impact on the resistance behavior of the material, [12] we have noted that a small amount of debris produced is to be expected, because of the direct effect of the interfacial material and fall out patches from the coatings interface.

\section{Conclusions}

The following conclusions are drawn from the above study:

- The successful fabrication of solanum fluid induced $\mathrm{Zn}-\mathrm{Al}-\mathrm{TiO}_{2}$ composite coatings was obtained from sulphate electrolyte.

- The addition of $\mathrm{TiO}_{2}$ concentration to the $\mathrm{Zn}$-Al sulphate bath altered the morphology and reduced the preferred orientation of the zinc hexagonal crystallite. 
- The observed structural modification as a result of embedded composite particles improved the microhardness properties of the composite coatings, as against the mild steel.

- A good anti-wear resistance property was exhibited from the produced coating.

\section{Acknowledgements}

This research study is based upon work financially supported by the National Research Foundation, South Africa. The equipment supported by Surface Engineering Research Centre (SERC) Tshwane University of Technology, Pretoria, is deeply appreciated.

\section{References}

1. Lee CK. Wear and Corrosion Behavior of Electrodeposited Nickel-Carbon Nanotube Composite Coatings on Ti-6Al-4V Alloy in Hanks Solution. Trib Inter. 2012;55:7-14

2. Choi Y, Baik NI, Hong SI. Microstructural Observation and Wear Properties of Thin Chrome Layers Prepared by Pulse Plating. Solid Films. 2001;397:24-29.

3. Lin Z, Li X, Xu L. Electrodeposition and Corrosion Behavior of ZincNickel Films Obtained from Acid Solutions: Effects of TEOS as Additive. Int J Electrochem Sci. 2012;7:12507-12517.

4. Fayomi OSI, Popoola API, Daniyan AA. Hybrid Effect of an In-situ Multilayer $\mathrm{Zn}-\mathrm{ZnO}-\mathrm{Cr}_{2} \mathrm{O}_{3}$ Electrodeposited Nano-Composite Coatings for Extended Application. Particulate Sci Technol. 2016. In press. http://dx.doi.org/10.1080/02726351.2016.1163305

5. Fayomi OSI, Popoola API, Olorunniwo OE. Structural and properties of $\mathrm{Zn}-\mathrm{A} 12 \mathrm{O} 3-\mathrm{SiC}$ nano-composite coatings by direct electrolytic process. Int J Adv Manufacturing Technol. 2016. In press. DOI 10.1007/s00170-0168428-4

6. Wang G, Zhu L, Liu H, et al. Zinc-Graphite Composite Coating for AntiFouling Application. J Mat Let. 2011;65:3095-3097.

7. Fayomi OSI, Popoola API. An Investigation of the Properties of Zn Coated Mild Steel. Int J Electro Sci. 2012;7: 6555-6570.

8. Xu R, Wang J, Guo Z, et al. Effect of Rare Earth on Microstructures and Properties of Ni-W-P-CeO $-\mathrm{SiO}_{2}$ Nano-composite Coating. J Rare Earth. 2008;26:579-583.

9. Gomes A, Frade T, Nogueira ID. Morphological Characterization of ZnBased Nanostructured thin films. Current Microscopy Contributions Adv Sci Technol. 2012;2:1146-1153.

10. Popoola API, Aigbodion VS, Fayomi OSI. Surface Characterization, mechanical properties and corrosion behaviour of ternary based $\mathrm{Zn}-\mathrm{ZnO}-$ $\mathrm{SiO}_{2}$ composite coating of mild steel. J Alloys Compd. 2016;654:561-566.

11. Thangaraj, Eliaz N, Chitharanjan A. Corrosion Behavior of Composition Modulated Multilayer Zn-Co Electrodeposits Produced Using a Single-bath 
Technique. J Appl Electrochem. 2009;39:339-345.

12. Blejan D, Muresan LM. Corrosion Behaviour of $\mathrm{Zn}-\mathrm{Ni}-\mathrm{Al}_{2} \mathrm{O}_{3}$ NXSAanocomposite Coatings Obtained by Electrodeposition from Alkaline Electrolytes. Mater Corros. 2012;63:1-6.

13. Fayomi OSI, Popoola API. Chemical Interaction, Interfacial Effect and Microstructural Characterization of the Induced Zinc-Aluminuim Solanium Tuberosum in Chloride Solution on Mild Steel. Res Chem Int. 2013;39:1354-1564.

14. Praveen BM, Venkatesha TV. Electrodeposition and Properties of Znnanosized $\mathrm{TiO}_{2}$ Composite Coatings. Appl Surf Sci. 2008;254:2418-2424.

15. Fayomi OSI, Popoola API, Loto CA, et al. Evaluation of Composition, Microstructure Characterization and Interfacial Properties of $\mathrm{Zn}-\mathrm{SnO} 2$ Metal Matrix Composite Coating. Prot Metals Phys Chem Surf. 2016;52:238-243.

16. Fayomi OSI, Popoola API, Oloruntoba DT. Nanoparticle Dispersion, Microstructure and Thermal Effect of Multi-doped ZrO2/SiC from Sulphate Induced Electrolyte. Prot Metals Phys Chem Surf. 2016;52:512-516. 